\title{
Artificially nanostructured n-type SiGe bulk thermoelectrics through plasma enhanced growth of alloy nanoparticles from the gas phase - CORRIGENDUM
}

\author{
N. Stein, N. Petermann, R. Theissmann, G. Schierning, R. Schmechel, and H. Wiggers \\ doi: 10.1557/jmr.2011.117, Published by Cambridge University Press, 7 June 2011.
}

In the last sentence of the abstract, " $1000{ }^{\circ} \mathrm{C} "$ is incorrect:

"A figure of merit of $z T=0.5+/-0.09$ at $450{ }^{\circ} \mathrm{C}$ and a peak $z T$ of $0.8+/-0.15$ at $1000^{\circ} \mathrm{C}$ could be achieved for a nanostructured, $0.8 \%$ phosphorus-doped $\mathrm{Si}_{80} \mathrm{Ge}_{20}$ alloy without any further optimization."
The correct temperature is $800{ }^{\circ} \mathrm{C}$.

\section{REFERENCE}

N. Stein, N. Petermann, R. Theissmann, G. Schierning, R. Schmechel, and H. Wiggers: Artificially nanostructured n-type SiGe bulk thermoelectrics through plasma enhanced growth of alloy nanoparticles from the gas phase. J. Mater. Res. 26(15), 1872 (2011). 